\title{
OPEN Chagas disease and SARS-CoV-2 coinfection does not lead to worse in-hospital outcomes
}

\begin{abstract}
Israel Molina $\mathbb{1}^{1,2,28}$, Milena Soriano Marcolino $\mathbb{1}^{3,4,28 \llbracket}$, Magda Carvalho Pires $\mathbb{1}^{5,28}$, Lucas Emanuel Ferreira Ramos $\mathbb{1}^{5}$, Rafael Tavares Silva $\mathbb{1}^{5}$, Milton Henriques Guimarães-Júnior $\mathbb{1}^{6}$, Isaias José Ramos de Oliveira $\mathbb{1}^{7}$, Rafael Lima Rodrigues de Carvalho $\mathbb{1}^{4}$, Aline Gabrielle Sousa Nunes $\mathbb{1}^{8}$, Ana Lara Rodrigues Monteiro de Barros $\rrbracket^{9,27}$, Ana Luiza Bahia Alves Scotton ${ }^{10}$, Angélica Aparecida Coelho Madureira $\mathbb{1}^{9,27}$, Bárbara Lopes Farace ${ }^{11}$, Cíntia Alcantara de Carvalho (12) Fernanda d'Athayde Rodrigues ${ }^{13}{ }^{13}$, Fernando Anschau $\circledast^{14,20}$, Fernando Antonio Botoni $\mathbb{D}^{7,15}$, Guilherme Fagundes Nascimento $\mathbb{1}^{8}$, Helena Duani ${ }^{7}{ }^{7,16}$, Henrique Cerqueira Guimarães $\mathbb{1}^{11}$, Joice Coutinho de Alvarenga ${ }^{12}$, Leila Beltrami Moreira $\mathbb{\circledR}^{4,13}$, Liege Barella Zandoná ${ }^{17,18}$, Luana Fonseca de Almeida $\mathbb{1}^{7}$, Luana Martins Oliveira $\mathbb{1}^{4,19}$, Luciane Kopittke $\mathbb{( 1 4}^{14,20}$, Luis César de Castro ${ }^{17,18}$, Luisa Elem Almeida Santos ${ }^{10,21}$, Máderson Alvares de Souza Cabral ${ }^{7,16}$, Maria Angélica Pires Ferreira $\mathbb{1}^{13}$, Natália da Cunha Severino Sampaio $\mathbb{1}^{22}$, Neimy Ramos de Oliveira $\mathbb{1}^{22}$, Pedro Ledic Assaf $\mathbb{D}^{9}$, Sofia Jarjour Tavares Starling Lopes $\mathbb{1}^{15,23}$, Tatiani Oliveira Fereguetti 22 , Veridiana Baldon dos Santos@14,20, Victor Eliel Bastos de Carvalho ${ }^{15,23}$, Yuri Carlotto Ramires ${ }^{18}$, Antonio Luiz Pinho Ribeiro ${ }^{3,4}$, Freddy Antonio Brito Moscoso ${ }^{24}$, Rogério Moura ${ }^{25}$, Carísi Anne Polanczyk ${ }^{4,13,26}$ \& Maria do Carmo Pereira Nunes ${ }^{7,16}$
\end{abstract}

\footnotetext{
${ }^{1}$ PROSICS Barcelona, Vall d'Hebron University Hospital, Passeig de la Vall d'Hebron, 119, 08035 Barcelona, Spain. ${ }^{2}$ Instituto René Rachou-FIOCRUZ Minas, Av. Augusto de Lima, 1715, Belo Horizonte, Brazil. ${ }^{3}$ Department of Internal Medicine, Medical School and Telehealth Center, University Hospital, Universidade Federal de Minas Gerais, Avenida Professor Alfredo Balena 190 Sala 246, Belo Horizonte, Brazil. ${ }^{4}$ Institute for Health Technology Assessment (IATS/ CNPq), Rua Ramiro Barcelos, 2359, Prédio 21 | Sala 507, Porto Alegre, Brazil. ${ }^{5}$ Department of Statistics, Universidade Federal de Minas Gerais, Av. Presidente Antônio Carlos, 6627, ICEx, Sala 4071, Belo Horizonte, Brazil. ${ }^{6} \mathrm{Hospital}$ Marcio Cunha, Av. Tsunawaki Avenue, 41, Ipatinga, Brazil. ${ }^{7}$ Medical School, Universidade Federal de Minas Gerais, Avenida Professor Alfredo Balena, 190, Belo Horizonte, Brazil. ${ }^{8} \mathrm{Hospital}$ UNIMED BH, Av. Do Contorno, Belo Horizonte 3097, Brazil. ${ }^{9}$ Hospital Metropolitano Doutor Célio de Castro, Rua Dona Luiza, 311, Belo Horizonte, Brazil. ${ }^{10} \mathrm{Hospital}$ Regional Antônio Dias, R. Maj. Gote, 1231, Patos de Minas, Brazil. ${ }^{11}$ Hospital Risoleta Tolentino Neves, Rua das Gabirobas, 01, Belo Horizonte, Brazil. ${ }^{12}$ Hospital João XXIII, Av. Professor Alfredo Balena, 400, Belo Horizonte, Brazil. ${ }^{13} \mathrm{Hospital}$ de Clínicas de Porto Alegre, Av. Ramiro Barcellos, 2350, Porto Alegre, Brazil. ${ }^{14} \mathrm{Hospital}$ Nossa Senhora da Conceição and Hospital Cristo Redentor, Av. Francisco Trein, 326, Porto Alegre, Brazil. ${ }^{15}$ Hospital Julia Kubitschek, R. Dr. Cristiano Rezende, 2745, Belo Horizonte, Brazil. ${ }^{16}$ Internal Medicine Department, University Hospital, Universidade Federal de Minas Gerais, Av. Prof Alfredo Balena, 110, Belo Horizonte, Brazil. ${ }^{17}$ Universidade do Vale do Taquari (UNIVATES), Av. Avelino Talini, 171, Lajeado, Brazil. ${ }^{18} \mathrm{Hospital}$ Bruno Born, Av. Benjamin Constant, 881, Lajeado, Brazil. ${ }^{19}$ Center for Research and Graduate Studies in Business Administration, Universidade Federal de Minas Gerais, Av. Presidente Antônio Carlos, 6627, Belo Horizonte, Brazil. ${ }^{20}$ Grupo Hospitalar Conceição, Hospital Nossa Senhora da Conceição, Av. Francisco Trein, 326, Porto Alegre, Brazil. ${ }^{21}$ Centro Universitário de Patos de Minas, R. Maj. Gote, 808, Patos de Minas, Brazil. ${ }^{22}$ Hospital Eduardo de Menezes, R. Dr. Cristiano Rezende, 2213, Belo Horizonte, Brazil. ${ }^{23}$ Pontífica Universidade Católica de Minas Gerais, Av. Dom José Gaspar, 500, Belo Horizonte, Brazil. ${ }^{24}$ Medical School of Fundação Educacional do Município de Assis, Av. Getúlio Vargas, 1200, Assis, Brazil. ${ }^{25} \mathrm{Hospital}$ Balbino - Rede D’or São Luiz, R. Angélica Mota, 90, Rio de Janeiro, Brazil. ${ }^{26}$ Internal Medicine Department, Universidade Federal do Rio Grande do Sul, Rua Ramiro Barcelos, 2359, Prédio 21 | Sala 507, Porto Alegre, Brazil. ${ }^{27}$ Faculdade de Ciências Médicas de Minas Gerais, Alameda Ezequiel Dias, 275, Belo Horizonte, MG CEP 30130-100, Brazil. ${ }^{28}$ These authors contributed equally: Israel Molina and Milena Soriano Marcolino. ${ }^{\boxplus e m a i l: ~ m i l e n a m a r c @ u f m g . b r ~}$
} 
Chagas disease (CD) continues to be a major public health burden in Latina America. Information on the interplay between COVID-19 and CD is lacking. Our aim was to assess clinical characteristics and in-hospital outcomes of patients with CD and COVID-19, and to compare it to non-CD patients. Consecutive patients with confirmed COVID-19 were included from March to September 2020. Genetic matching for sex, age, hypertension, diabetes mellitus and hospital was performed in a 4:1 ratio. Of the 7018 patients who had confirmed COVID-19, 31 patients with CD and 124 matched controls were included (median age 72 (64-80) years-old, $44.5 \%$ were male). At baseline, heart failure ( $25.8 \%$ vs. $9.7 \%$ ) and atrial fibrillation ( $29.0 \%$ vs. $5.6 \%$ ) were more frequent in CD patients than in the controls $(p<0.05)$. C-reactive protein levels were lower in CD patients compared with the controls $(55.5$ $[35.7,85.0]$ vs. $94.3[50.7,167.5] \mathrm{mg} / \mathrm{dL})$. In-hospital management, outcomes and complications were similar between the groups. In this large Brazilian COVID-19 Registry, CD patients had a higher prevalence of atrial fibrillation and chronic heart failure compared with non-CD controls, with no differences in-hospital outcomes. The lower C-reactive protein levels in CD patients require further investigation.

Since the first case of coronavirus disease 19 (COVID-19) described in Brazil on February 26th, 2020, SARS-CoV 2 infection has evolved as a global pandemic. The disease has a wide spectrum of clinical manifestations, ranging from asymptomatic cases to severe pneumonia and acute respiratory distress syndrome ${ }^{1,2}$.

Although the great majority of symptoms are unspecified, mild, flu-like or belonging to respiratory sphere, other organs could be affected, as the cardiovascular system. COVID-19 has been associated with multiple cardiac manifestations, including cardiac arrhythmias, myocardial infarction, acute heart failure and acute fulminant myocarditis. Cardiovascular involvement has shown to be associated with increased mortality ${ }^{3,4}$.

Underlying comorbidities have been widely associated with a worse prognosis for COVID-19 patients, since viral infections could act as triggers for worsening of chronic diseases ${ }^{5-7}$. Chagas disease (CD) is a multisystemic disorder, potentially affecting, cardiovascular, digestive, and neurological systems. It is the most common cause of infectious cardiomyopathy worldwide, and it may play a role in the clinical prognosis of COVID-19 patients ${ }^{8,9}$. Although CD is endemic in Latin America, it has been recognized that the disease is now a worldwide concern, as the disease spread with population movements from endemic to non-endemic countries ${ }^{10}$. In Brazil, CD still remains a public health challenge, being one the countries with more absolute number of patients and an annual incidence rate of approximately 0.16 per 100,000 inhabitants/year ${ }^{11}$.

Potential interactions between COVID-19 and Chagas cardiomyopathy could be probable, because both conditions share the same immunological pathway. SARS-CoV-2 spike proteins bind to angiotensin-converting enzyme-2 (ACE-2), which is needed to invade the host cell. On the other hand, ACE2 is involved in heart function and the development of hypertension and diabetes mellitus (DM), risk factors frequently observed in patients with chronic Chagas cardiomyopathy ${ }^{12,13}$. Those patients could have increased levels of ACE2 because of the chronic use of ACE inhibitors and/or angiotensin receptor blockers (ARBs).

Limited information is available regarding the characteristics and outcomes of patients with CD and COVID19. Therefore, we aim to describe the characteristics, laboratory, and imaging findings, as well as in-hospital outcomes of CD and COVID-19 coinfected patients included in the Brazilian COVID-19 Registry.

\section{Methods}

This manuscript adheres to the Strengthening the Reporting of Observational Studies in Epidemiology (STROBE) guideline ${ }^{14}$. All methods were performed in accordance with the relevant guidelines and regulations.

Study design and subjects. Patients were selected from the Brazilian COVID-19 Registry, a prospective multicenter cohort project with 37 participant hospitals in 17 cities from three Brazilian states (Minas Gerais, Pernambuco, Rio Grande do Sul, Santa Catarina, São Paulo). Details of the cohort were published elsewhere.

COVID-19 diagnosis was confirmed through real time polymerase-chain reaction (RT-PCR) nasopharyngeal and oropharyngeal swab testing or anti-SARS-CoV-2 IgM detected in serological assay in serum or plasma sample, according to World Health Organization guidance ${ }^{15}$.

For the present study, patients with previous history of CD recorded in the database were selected. CD diagnosis were retrieved by their own hospital record or self-referred by the patient. Patients were admitted from March 1 to September 30, 2020. At the moment of the analysis 7018 patients were introduced in the registry, 31 of those were classified as suffering from CD.

Data collection. Study data were collected by trained hospital staff or interns using Research Electronic Data Capture (REDCap) tools ${ }^{16}$. Medical records were reviewed to collect data on patients' demographic and clinical characteristics, including age, sex, pre-existing medical conditions and home medications; COVID-19 symptoms at hospital presentation; clinical assessment upon hospital admission, third and fifth admission days; laboratory, imaging, electrocardiographic data; inpatient medications, treatment and outcomes. Definitions were published elsewhere ${ }^{5}$. 


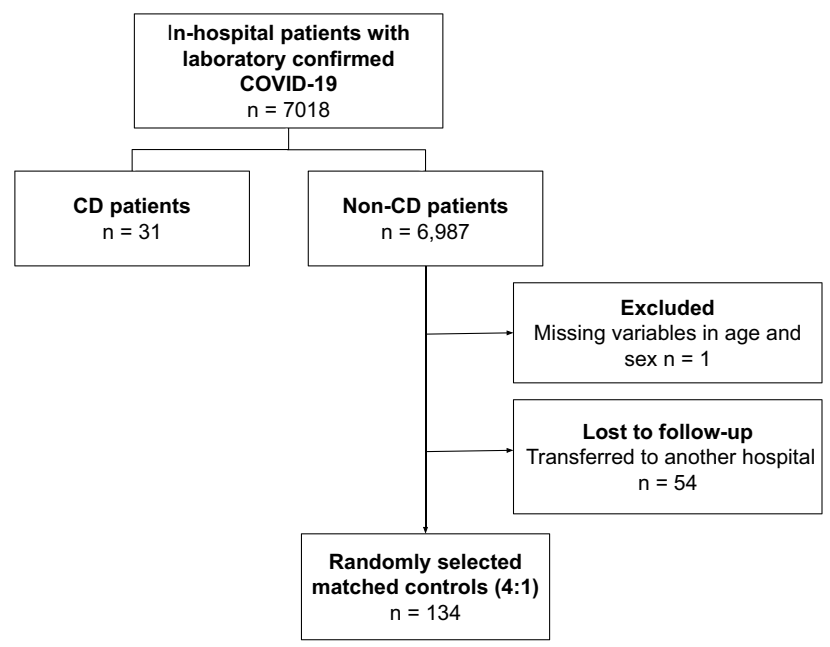

Figure 1. Flowchart of COVID-19 patients included in the study.

Patient and public involvement. This was an urgent public health research study in response to a Public Health Emergency of International Concern. Patients or the public were not involved in the design, conduct, interpretation or presentation of results of this research.

Statistical analysis. Genetic matching for sex, age, hypertension, DM and hospital was performed in a 4:1 ratio (MatchIt package in $\mathrm{R}$ ). Genetic matching is a multivariate matching method that uses an evolutionary search algorithm to determine the weight each covariate is given, to maximize the balance of observed covariates across individuals of both groups ${ }^{17}$. Sample size of 132 controls was calculated considering and expected risk ratio for mortality 2.5 in CD-group, power of $80 \%$, alfa-error probability of $5 \%$ for a $4: 1 \mathrm{CD} /$ control.

Categorical data were presented as absolute numbers and proportions, and continuous variables were expressed as medians and interquartile ranges. The $\chi^{2}$ and Fisher Exact test were used to compare the distribution of categorical variables, and the Wilcoxon-Mann-Whitney test for continuous variables. Results were considered statistically significant if the two-tailed $\mathrm{p}$-value was $<0.05$. All statistical analysis was performed with R software (version 4.0.2).

Ethics. The study was approved by the National Commission for Research Ethics (CAAE 30350820.5.1001.0008). Individual informed consent was waived by the National Commission for Research Ethics owing to the pandemic situation and the use of deidentified data, based on medical chart review only.

Transparency declaration. The lead authors (MSM, IM and MCP) affirm that the manuscript is an honest, accurate, and transparent account of the study being reported; that no important aspects of the study have been omitted; and that any discrepancies from the study as originally planned (and, if relevant, registered) have been explained.

\section{Results}

Patient characteristics at hospital admission. From the 155 patients included in the study (Fig. 1), 31 were reported as having Chagas disease, and 124 were matched controls. The median age was 72.0 (64.0-79.5) years-old and 44.5\% were male. Hypertension (65.8\%), DM (32.3\%), chronic obstructive pulmonary disease (COPD) in (16.7\%), chronic heart failure $(12.9 \%)$ and atrial fibrillation $(10.3 \%)$ were the most frequent comorbidities. All patients were diagnosed for COVID-19 through a positive RT-PCR for SARS-CoV-2.

Patients were from 11 hospitals, with average 382 beds (ranging from 60 to 936 beds). Nine of them (81.8\%) were public, 7 (63.6\%) were teaching hospitals and 8 (72.7\%) were reference centers for COVID-19 treatment.

When comparing CD patients with controls (Table 1), there were no significant differences in demographic and medical characteristics, except for the prevalence of chronic heart failure (8 [25.8\%] vs 12 [9.7\%]; $\mathrm{p}=0.031)$ and atrial fibrillation $(9[29.0 \%]$ vs 7 [5.6\%]; $\mathrm{p}<0.001)$, which were more prevalent in CD patients. Although the median number of comorbidities was higher in CD patients $(3.0[2.0,4.0]$ vs. $2.0[1.0,3.0])$, this difference did not reach statistical significance $(\mathrm{p}=0.119)$.

The median time since from symptom onset to hospital admission was 6 (8-4) days. Dyspnea and cough (dry or productive) were present in more than one half of patients. There were no differences in the clinical presentation between both groups (Table 2).

Laboratory and imaging findings are presented in Supplementary Table S1 and S2. Median C-reactive protein was lower in CD patients than the controls $(55.5[35.7,85.0]$ vs. $94.3[50.7,167.5] \mathrm{mg} / \mathrm{dL})$. There was no other clinically relevant difference in laboratory exams between groups. 


\begin{tabular}{|c|c|c|c|}
\hline & CD patients $(n=31)$ & Controls $(n=124)$ & p-value \\
\hline Age $^{\star}$ (years) & $74.0(64.5,79.0)$ & $72.0(64.0,80.0)$ & 0.856 \\
\hline Male sex ${ }^{*}$ & $14(45.2 \%)$ & $55(44.4 \%)$ & $>0.999$ \\
\hline \multicolumn{4}{|l|}{ Comorbidities $^{* *}$} \\
\hline \multicolumn{3}{|l|}{ Total number } & 0.461 \\
\hline 0 & $3(9.7 \%)$ & $11(8.9 \%)$ & \\
\hline 1 & $3(9.7 \%)$ & $27(21.8 \%)$ & \\
\hline 2 & $9(29.0 \%)$ & $39(31.5 \%)$ & \\
\hline 3 & $7(22.6 \%)$ & $26(21.0 \%)$ & \\
\hline 4 & $6(19.4 \%)$ & $16(12.9 \%)$ & \\
\hline$\geq 5$ & $3(9.7 \%)$ & $5(4.0 \%)$ & \\
\hline \multicolumn{4}{|l|}{ Cardiovascular diseases } \\
\hline Hypertension ${ }^{*}$ & $20(64.5 \%)$ & $82(66.1 \%)$ & $>0.999$ \\
\hline Ischemic cardiopathy & $1(3.2 \%)$ & $6(4.8 \%)$ & $>0.999$ \\
\hline Chronic heart failure & $8(25.8 \%)$ & $12(9.7 \%)$ & 0.031 \\
\hline Atrial fibrillation/flutter & $9(29.0 \%)$ & $7(5.6 \%)$ & $<0.001$ \\
\hline Stroke & $2(6.5 \%)$ & $8(6.5 \%)$ & $>0.999$ \\
\hline Pacemaker & $1(3.2 \%)$ & $0(0.0 \%)$ & 0.200 \\
\hline \multicolumn{4}{|l|}{ Respiratory diseases } \\
\hline Asthma & $1(3.2 \%)$ & $9(7.3 \%)$ & 0.688 \\
\hline COPD & $8(25.8 \%)$ & $18(14.5 \%)$ & 0.216 \\
\hline \multicolumn{4}{|l|}{ Metabolic diseases } \\
\hline Diabetes mellitus* & $10(32.3 \%)$ & $40(32.3 \%)$ & $>0.999$ \\
\hline Obesity $(\mathrm{BMI}>30)$ & $1(3.2 \%)$ & $10(8.1 \%)$ & 0.695 \\
\hline \multicolumn{4}{|l|}{ Other conditions } \\
\hline Cirrhosis & $0(0.0 \%)$ & $2(1.6 \%)$ & $>0.999$ \\
\hline Psychiatric condition & $1(3.2 \%)$ & $9(7.3 \%)$ & 0.688 \\
\hline Chronic renal disease & $0(0.0 \%)$ & $3(2.4 \%)$ & $>0.999$ \\
\hline Dyslipidemia & $0(0.0 \%)$ & $1(0.8 \%)$ & $>0.999$ \\
\hline HIV & $0(0.0 \%)$ & $2(1.6 \%)$ & $>0.999$ \\
\hline Neoplasia & $3(9.7 \%)$ & $8(6.5 \%)$ & 0.461 \\
\hline Transplantation & $1(3.2 \%)$ & $3(2.4 \%)$ & $>0.999$ \\
\hline Dementia & $0(0.0 \%)$ & $1(0.8 \%)$ & $>0.999$ \\
\hline Epilepsy & $0(0.0 \%)$ & $0(0.0 \%)$ & - \\
\hline \multicolumn{4}{|l|}{ Toxic habits } \\
\hline Alcohol & $1(3.2 \%)$ & $6(4.8 \%)$ & $>0.999$ \\
\hline Tobacco (active or former) & $7(22.6 \%)$ & $35(28.2 \%)$ & 0.684 \\
\hline
\end{tabular}

Table 1. Demographic characteristics and medical history data of the study population at baseline. Numbers are presented are medians (P25-P75) or counts (percentages). BMI body mass index, CD Chagas disease, $C O P D$ chronic obstructive pulmonary disease. ${ }^{\star}$ Controls were paired for age, sex, hospital, hypertension and diabetes. ${ }^{*}$ This variable does not include Chagas disease.

At admission, diffuse interstitial infiltrate pattern and ground glass opacities were the most prevalent findings in the chest X-ray and chest computer tomography (CT), respectively. No significant differences were found in the frequency of abnormalities and radiological progression in both groups, expect for the frequency of pleural effusion in the follow-up CT, more frequent in CD patients.

Among CD, patients 10 had an EKG performed. Of those, 4 patients had atrial fibrillation and 2 had a pacemaker rhythm, so the proportion of patients with sinus rhythm in controls were significantly higher than in CD patients $(68.8 \%$ vs $40.0 \%, \mathrm{p}=0.142)$ (Table 3$)$.

Treatment and clinical outcomes. There were no differences regarding the therapeutic strategy among both groups (Table 4), except for a trend of higher frequency of therapeutic anticoagulation in CD patients ( $19.3 \%$ vs. $10.5 \%, p=0.206)$. Twenty-four CD patients $(77.4 \%)$ and 103 controls $(83.0 \%)$ received corticosteroids $(\mathrm{p}=0.448)$. Dexamethasone was used by $64.5 \% \mathrm{CD}$ patients and $66.1 \%$ controls $(\mathrm{p}>0.999)$. Macrolides were prescribed for $77.4 \%$ in CD patients and $87.1 \%$ controls $(\mathrm{p}=0.255)$; chloroquine or hydroxychloroquine in $3.2 \%$ and $4.8 \%$ ( $p>0.999)$. Only one patient received remdesivir.

During hospitalization, $72(46.5 \%)$ of patients required admission to the intensive care unit, and among them $55(35.4 \%)$ needed mechanical ventilation and $26(16.8 \%)$ substitutive renal therapy. Overall, there were no differences in in terms of clinical evolution and outcomes (Table 5). 


\begin{tabular}{|c|c|c|c|c|c|}
\hline & \multicolumn{2}{|l|}{ CD patients $(n=31)$} & \multicolumn{2}{|l|}{ Controls $(n=124)$} & \multirow[b]{2}{*}{ p-value } \\
\hline & $\begin{array}{l}\text { Frequency (\%) or median } \\
\text { (IQR) }\end{array}$ & Valid cases & $\begin{array}{l}\text { Frequency (\%) or median } \\
\text { (IQR) }\end{array}$ & Valid cases & \\
\hline \multicolumn{6}{|l|}{ Symptoms } \\
\hline Time from symptom onset & $5.0(3.0,7.8)$ & 30 & $6.0(3.8,9.2)$ & 124 & 0.392 \\
\hline Adynamic & $10(32.3 \%)$ & 31 & $37(29.8 \%)$ & 124 & 0.965 \\
\hline Ageusia & $4(12.9 \%)$ & 31 & $7(5.6 \%)$ & 124 & 0.232 \\
\hline Anosmia & $5(16.1 \%)$ & 31 & $10(8.1 \%)$ & 124 & 0.183 \\
\hline Headache & $7(22.6 \%)$ & 31 & $22(17.7 \%)$ & 124 & 0.719 \\
\hline Rhinorrhea & $4(12.9 \%)$ & 31 & $20(16.1 \%)$ & 124 & 0.786 \\
\hline Diarrhea & $3(9.7 \%)$ & 31 & $18(14.5 \%)$ & 124 & 0.573 \\
\hline Dyspnea & $19(61.3 \%)$ & 31 & $73(58.9 \%)$ & 124 & 0.967 \\
\hline Odynophagia & $14(45.2 \%)$ & 31 & $64(51.6 \%)$ & 124 & 0.659 \\
\hline Fever & $4(12.9 \%)$ & 31 & $17(13.7 \%)$ & 124 & $>0.999$ \\
\hline Hyporexia & $1(3.2 \%)$ & 31 & $5(4.0 \%)$ & 124 & $>0.999$ \\
\hline Neurological manifestations & $6(19.4 \%)$ & 31 & $34(27.4 \%)$ & 124 & 0.491 \\
\hline Myalgia & $2(6.5 \%)$ & 31 & $19(15.3 \%)$ & 124 & 0.252 \\
\hline Nausea/vomiting & $7(22.6 \%)$ & 31 & $21(16.9 \%)$ & 124 & 0.639 \\
\hline Productive cough & $18(58.1 \%)$ & 31 & $65(52.4 \%)$ & 124 & 0.717 \\
\hline Dry cough & $1(3.2 \%)$ & 31 & $1(0.8 \%)$ & 124 & 0.361 \\
\hline \multicolumn{6}{|l|}{ Clinical assessment } \\
\hline Glasgow $<15$ & $6(19.4 \%)$ & 31 & $24(19.4 \%)$ & 124 & $>0.999$ \\
\hline HR & $80.0(72.0,86.8)$ & 30 & $84.0(77.0,96.0)$ & 121 & 0.060 \\
\hline $\mathrm{HR} \geq 100 \mathrm{bpm}$ & $4(12.9 \%)$ & 31 & $28(22.6 \%)$ & 124 & 0.346 \\
\hline $\mathrm{RR}$ & $22.0(18.5,26.0)$ & 27 & $22.0(18.0,25.0)$ & 115 & 0.748 \\
\hline $\mathrm{RR} \geq 24$ irpm & $16(51.6 \%)$ & 31 & $56(45.2 \%)$ & 124 & 0.658 \\
\hline Sat O2 & $94.0(91.0,96.0)$ & 29 & $94.0(90.0,96.0)$ & 123 & 0.712 \\
\hline Sat $\mathrm{O} 2<90 \%$ & $7(22.6 \%)$ & 31 & $28(22.6 \%)$ & 124 & $>0.999$ \\
\hline SF ratio & $402.4(300.0,440.5)$ & 28 & $395.8(240.0,438.1)$ & 123 & 0.316 \\
\hline Invasive ventilation & $3(9.7 \%)$ & 31 & $13(10.5 \%)$ & 124 & $>0.999$ \\
\hline $\mathrm{SBP} \leq 100 \mathrm{mmHg}$ & $1(3.2 \%)$ & 31 & $11(8.9 \%)$ & 124 & 0.462 \\
\hline Inotropic drugs & $12(38.7 \%)$ & 31 & $45(36.3 \%)$ & 124 & 0.967 \\
\hline
\end{tabular}

Table 2. Clinical characteristics of the study population at baseline. $C D$ Chagas disease, $H R$ hear rate, $I Q R$ interquartile range, $R R$ respiratory rate, $S F$ ratio $\mathrm{Sat}_{2} / \mathrm{FiO}_{2}$, valid cases non missing cases.

\section{Discussion}

We described a cohort of CD patients infected with SARS-COV-2 and admitted in hospitals belonging to a large Brazilian COVID-19 Registry project. Overall, CD patients had similar clinical characteristics and outcomes to non-CD controls, matched by age, sex, hypertension, DM and hospital, except from a higher prevalence of atrial fibrillation and chronic heart failure, and lower C-reactive protein levels.

Due to the potential cardiac involvement, and the higher procoagulant state, T.cruzi and SARS-COV-2 coinfection has been postulated as condition for myocardial damage, depression of ventricular function, increased arrhythmogenic state, thromboembolism risk, and ultimately a worst prognosis ${ }^{18-20}$. However, it was only a hypothesis and no previous study has tested it using patient data. Despite the limited number of patients with CD (31) our study refuted did not confirm the hypothesis. We did not find any significant difference or even a trend of worse clinical outcomes in CD patients, even with a higher frequency of atrial fibrillation and heart failure in the CD group.

Current data demonstrates that SARS-CoV-2 infection induces immune dysfunction, widespread endothelial injury, complement-associated coagulopathy and systemic microangiopathy ${ }^{21}$. By the other hand, T. cruzi infection is associated with an upregulated procoagulant activity in plasma. Therefore, it could be expected a greater risk of thromboembolic manifestations. In our cohort the overall thrombosis event was $4.5 \%$ (7 out of 155), all of them were in the control group. Noteworthy that, the great majority of patients (91\%) were treated with oral anticoagulants because its underlying disease or received any kind of prophylactic heparin when admitted to the hospital, as recommended by national and international guidelines for the management of in-hospital COVID-19 patients $^{22,23}$.

The lower median C-reactive level in CD patients was an unexpected finding. We hypothesize that CD patients, as they already have an active chronic inflammatory and immune response triggered by T. cruzi infection, might have a lower risk of unregulated inflammatory response to COVID-19 ${ }^{24}$. Therefore, what could have been a factor for worse prognosis, due to a higher frequency of associated heart failure and atrial fibrillation and the $\mathrm{CD}$ itself, could be equilibrated by a controlled inflammatory response. This is only a hypothesis, that merits 


\begin{tabular}{|l|l|l|r|}
\hline & CD patients $(\mathbf{n}=31)$ & Control patients $(\mathbf{n}=\mathbf{1 2 4})$ & p-value \\
\hline ECG at admission & $10(32.3 \%)$ & $32(26.0 \%)$ & 0.637 \\
\hline Sinus rhythm & $4(40.0 \%)$ & $22(68.8 \%)$ & 0.142 \\
\hline Atrial fibrillation or flutter & $4(40.0 \%)$ & $7(21.9 \%)$ & 0.410 \\
\hline Pacemaker & $2(20.0 \%)$ & $1(3.1 \%)$ & 0.136 \\
\hline Right bundle branch block & $1(10.0 \%)$ & $4(12.5 \%)$ & $>0.999$ \\
\hline Left bundle branch block & $2(20.0 \%)$ & $1(3.1 \%)$ & 0.136 \\
\hline Left ventricular hemiblock & $0(0.0 \%)$ & $0(0.0 \%)$ & $>0.999$ \\
\hline New electrocardiographic abnormalities ${ }^{*}$ & $\mathrm{~N}^{*}=4(12.9 \%)$ & $\mathrm{N} \times 15(12.3 \%)$ & 0.087 \\
\hline Rhythm & & & 0.211 \\
\hline Atrial fibrillation or flutter & $4(100.0 \%)$ & $6(40.0 \%)$ & $>0.999$ \\
\hline Pacemaker & $1(25.0 \%)$ & $0(0.0 \%)$ & $>0.999$ \\
\hline Multifocal atrial rhythm & $0(0.0 \%)$ & $1(6.7 \%)$ & $>0.999$ \\
\hline Supraventricular tachycardia & $0(0.0 \%)$ & $1(6.7 \%)$ & $>0.999$ \\
\hline Monomorphic ventricular tachycardia & $0(0.0 \%)$ & $3(20.0 \%)$ & 0.530 \\
\hline Polymorphic ventricular tachycardia & $0(0.0 \%)$ & $1(6.7 \%)$ & 0.530 \\
\hline No new rhythm abnormalities & $0(0.0 \%)$ & $4(26.7 \%)$ & 0.557 \\
\hline New long QTc interval & $1(25.0 \%)$ & $2(13.3 \%)$ & $4(26.7 \%)$ \\
\hline None & $2(50.0 \%)$ & & \\
\hline
\end{tabular}

Table 3. Electrocardiographic characteristics of the study population at baseline and new abnormalities at follow-up. ${ }^{\star} \mathrm{New}$ electrocardiographic abnormalities through in-hospital follow-up, and number of patients in which this outcome was assessed. CD Chagas disease, ECG electrocardiogram, QTc corrected QT interval.

\begin{tabular}{|l|l|l|r|}
\hline \multicolumn{1}{|l|}{ CD patients (n=31) } & Controls (n=124) & p-value \\
\hline Azithromycin & $23(74.2 \%)$ & $91(73.4 \%)$ & $>0.999$ \\
\hline Clarithromycin & $1(3.2 \%)$ & $17(13.7 \%)$ & 0.126 \\
\hline Chloroquine & $0(0.0 \%)$ & $1(0.8 \%)$ & $>0.999$ \\
\hline Hydroxycloroquine & $1(3.2 \%)$ & $5(4.0 \%)$ & $>0.999$ \\
\hline Remdesivir & $2(0.0 \%)$ & $>0.999$ \\
\hline Anticoauglation & \multicolumn{3}{|l|}{} \\
\hline Profilatic & \multicolumn{4}{|l|}{} \\
\hline Low-molecular-weight & $16(51.6 \%)$ & $65(52.4 \%)$ & $>0.999$ \\
\hline Non-fractioneted & $11(35.5 \%)$ & $58(46.8 \%)$ & 0.353 \\
\hline Fondaparinoux & $0(0.0 \%)$ & $1(0.8 \%)$ & $>0.999$ \\
\hline Therapeutic & $0(0.0 \%)$ & $1(0.8 \%)$ & $>0.999$ \\
\hline Low-molecular-weight & $5(16.1 \%)$ & $8(6.5 \%)$ & 0.138 \\
\hline Non-fractioneted & $1(3.2 \%)$ & $5(4.0 \%)$ & $>0.999$ \\
\hline
\end{tabular}

Table 4. Medications.

consideration for future studies. If proved correct, it may add to the knowledge of understating how to prevent the unregulated inflammatory response in COVID-19.

It is also interesting to discuss the influence that the use of anticoagulants in full doses may have had on the outcomes of patients with CD and COVID-19. The higher prevalence of atrial fibrillation in those patients may had led to a higher frequency of use of therapeutic dosage anticoagulants (19.3\% vs. 10.5\%), which did not reach statistical significance due to the sample size. The best strategy to be used-prophylactic or therapeutic heparin doses-in patients with moderate to severe COVID-19 is not yet defined, and it has been hypothesized that therapeutic anticoagulation (full dose heparin) is associated with decreased in-hospital mortality in patients with moderate COVID-19, but not in patients with severe COVID-19.

It is known the effect of immunosuppressant drugs and the risk of reactivation of CD. In the case of corticosteroids, immunosuppressive doses have not been associated with higher rates of reactivation of CD, although is controversial due to the lack of supporting evidence ${ }^{25,26}$. Tocilizumab, a cytokine inhibitor (recombinant humanized monoclonal antibody with an antagonist effect on the IL-6 receptor), combined with another immunosuppressant agents have been suggested to be associated with the reactivation of latent infections, including parasites.

Two published case reports of Strongyloides Hyperinfection Syndrome in COVID-19 patients immunosuppressed with dexamethasone and tocilizumab, have been recently published ${ }^{27,28}$. To date, no cases of CD reactivation have been published, but at least, there is a concern that COVID-19 disease therapeutics could potentially 


\begin{tabular}{|l|l|l|l|l|r|}
\hline & \multicolumn{2}{l}{ CD patients $(\mathbf{n}=\mathbf{3 1})$} & \multicolumn{2}{l|}{ Control patients (n=124) } & Valid \\
\cline { 2 - 6 } & $\begin{array}{l}\text { Frequency (\%) or median } \\
(\mathbf{I Q R})\end{array}$ & Valid cases & $\begin{array}{l}\text { Frequency (\%) or median } \\
(\mathbf{I Q R})\end{array}$ & Value \\
\hline Length of stay & $8.0(4.5,13.5)$ & 31 & $10.0(7.0,17.0)$ & 124 & 0.220 \\
\hline Admission to ICU & $16(51.6 \%)$ & 31 & $56(45.2 \%)$ & 124 & 0.658 \\
\hline $\begin{array}{l}\text { Time from admission to ICU } \\
\text { (days) }\end{array}$ & $1.0(0.0,2.0)$ & 16 & $0.5(0.0,2.0)$ & 56 & 0.891 \\
\hline Days in ICU & $6.0(2.0,11.2)$ & 16 & $7.5(4.0,14.0)$ & 56 & 0.352 \\
\hline Thromboembolic events & $0(0.0 \%)$ & 31 & $7(5.6 \%)$ & 124 & 0.346 \\
\hline Mechanical ventilation & $10(32.3 \%)$ & 31 & $45(36.3 \%)$ & 124 & 0.834 \\
\hline Acute kidney injury & $9(37.5 \%)$ & 24 & $45(41.7 \%)$ & 108 & 0.884 \\
\hline RRT & $5(16.1 \%)$ & 31 & $21(16.9 \%)$ & 124 & $>0.999$ \\
\hline Sepsis & $6(19.4 \%)$ & 31 & $24(19.4 \%)$ & 124 & $>0.999$ \\
\hline Nosocomial infection & $3(9.7 \%)$ & 31 & $24(19.4 \%)$ & 124 & 0.314 \\
\hline Acute heart failure & $2(6.5 \%)$ & 31 & $5(4.0 \%)$ & 124 & 0.628 \\
\hline Acute respiratory distress & $9(29.0 \%)$ & 31 & $44(35.5 \%)$ & 124 & 0.641 \\
\hline Death & $10(32.3 \%)$ & 31 & $38(30.6 \%)$ & 124 & $>0.999$ \\
\hline
\end{tabular}

Table 5. Clinical outcomes. $C D$ chagas disease, $I C U$ intensive care unit, $I Q R$ interquartile range, $R R T$ renal replacement therapy.

trigger reactivation of $\mathrm{CD}$. This merits further investigation and until definitive evidence is published, it should be a cause of concern in decision making, when prescribing immunosuppressors in these patients.

The fact that the majority of CD patients were admitted to public hospitals $(81.8 \%)$ is an indicator that CD disproportionally affects people from lower income background. In a previous multivariate analysis, we demonstrated that despite being admitted to public hospitals patients do not have worse prognosis than patients admitted to private ones ${ }^{5}$.

This study has limitations. In addition to the retrospective design, subject to the drawbacks of a patient records review, the number of $\mathrm{CD}$ was low. However, it is the largest series published to date. Due to the pragmatic study design, laboratory and imaging tests were performed at the discretion of the treating physician. In that sense, Chagas disease diagnosis was based on medical records or by self-reporting, in these cases no extra serology was performed. Despite the limited representativity of radiologic, tomographic and electrocardiographic analysis, no patient performed echocardiogram during hospital admission.

\section{Conclusions}

Although coinfection by Trypanosoma cruzi and SARS-COV-2 may pose a risk of complications and therefore a worse prognosis, in our series we did not find significant differences in terms of clinical presentation and outcomes of patients with CD compared to controls, despite a higher frequency of chronic heart failure and atrial fibrillation at baseline. We observed lower C-reactive protein levels in $\mathrm{CD}$ when compared to controls, and this merits further investigation.

\section{Data availability}

Data are available upon reasonable request.

Received: 13 May 2021; Accepted: 9 August 2021

Published online: 13 October 2021

\section{References}

1. Guan, W.-J. et al. Clinical characteristics of coronavirus disease 2019 in China. N. Engl. J. Med. 382, 1708-1720. https://doi.org/ 10.1056/NEJMoa2002032 (2020).

2. Rodriguez-Morales, A. J. et al. Clinical, laboratory and imaging features of COVID-19: A systematic review and meta-analysis. Travel Med. Infect. Dis. 34, 101623. https://doi.org/10.1016/j.tmaid.2020.101623 (2020).

3. Madjid, M. et al. Potential effects of coronaviruses on the cardiovascular system: A review. JAMA Cardiol. 5, 831-840. https://doi. org/10.1001/jamacardio.2020.1286 (2020).

4. Zheng, Y.-Y. et al. COVID-19 and the cardiovascular system. Nat. Rev. Cardiol. 17, 259-260. https://doi.org/10.1038/s41569-0200360-5 (2020).

5. Marcolino, M. S. et al. Clinical characteristics and outcomes of patients hospitalized with COVID-19 in Brazil: Results from the Brazilian COVID-19 Registry. Int. J. Infect. Dis. Off. Publ. Int. Soc. Infect. Dis. https://doi.org/10.1016/j.ijid.2021.01.019 (2021).

6. Marcolino, M. S. et al. ABC2-SPH risk score for in-hospital mortality in COVID-19 patients: Development, external validation and comparison with other available scores. MedRxiv. https://doi.org/10.1101/2021.02.01.21250306 (2021).

7. Knight, S. R. et al. Risk stratification of patients admitted to hospital with covid-19 using the ISARIC WHO clinical characterisation protocol: Development and validation of the 4C mortality score. BMJ 370, m3339. https://doi.org/10.1136/bmj.m3339 (2020).

8. de Andrade, J. P. et al. I Latin American guidelines for the diagnosis and treatment of Chagas cardiomyopathy. Arq. Bras. Cardiol. 97, 1-48 (2011).

9. Pérez-Molina, J. A. \& Molina, I. Chagas disease. Lancet Lond. Engl. 391, 82-94. https://doi.org/10.1016/S0140-6736(17)31612-4 (2018). 
10. Coura, J. R. \& Viñas, P. A. Chagas disease: A new worldwide challenge. Nature 465, S6-S7. https://doi.org/10.1038/nature09221 (2010).

11. WHO. Chagas disease in Latin America: An epidemiological update based on 2010 estimates. Wkly. Epidemiol Rec. Health Sect. Secr. Leag. Nations 90, 33-43 (2015).

12. Zhou, D., Dai, S.-M. \& Tong, Q. COVID-19: A recommendation to examine the effect of hydroxychloroquine in preventing infection and progression. J. Antimicrob. Chemother. https://doi.org/10.1093/jac/dkaa114 (2020).

13. Zaidel, E. J. et al. COVID-19: Implications for people with Chagas disease. Glob Heart. https://doi.org/10.5334/gh.891 (2020).

14. von Elm, E. et al. Strengthening the reporting of observational studies in epidemiology (STROBE) statement: Guidelines for reporting observational studies. BMJ 335, 806-808. https://doi.org/10.1136/bmj.39335.541782.AD (2007).

15. WHO-2019-nCoV-laboratory-2020.6-por.pdf. https://apps.who.int/iris/bitstream/handle/10665/334254/WHO-2019-nCoV-labor atory-2020.6-por.pdf (Accessed 21 March 2021).

16. Harris, P. A. et al. Research electronic data capture (REDCap)-A metadata-driven methodology and workflow process for providing translational research informatics support. J. Biomed. Inf. 42, 377-381. https://doi.org/10.1016/j.jbi.2008.08.010 (2009).

17. Diamond, A. \& Sekhon, J. S. Genetic matching for estimating causal effects: A general multivariate matching method for achieving balance in observational studies. Rev. Econ. Stat. 95(3), 932-945 (2013).

18. Guzik, T. J. et al. COVID-19 and the cardiovascular system: Implications for risk assessment, diagnosis, and treatment options. Cardiovasc. Res. https://doi.org/10.1093/cvr/cvaa106 (2020).

19. Siripanthong, B. et al. Recognizing COVID-19-related myocarditis: The possible pathophysiology and proposed guideline for diagnosis and management. Heart Rhythm 17, 1463-1471. https://doi.org/10.1016/j.hrthm.2020.05.001 (2020).

20. Pinazo, M.-J. et al. Altered hypercoagulability factors in patients with chronic chagas disease: Potential biomarkers of therapeutic response. PLoS Negl. Trop. Dis. 10, e0004269. https://doi.org/10.1371/journal.pntd.0004269 (2016).

21. Perico, L. et al. Immunity, endothelial injury and complement-induced coagulopathy in COVID-19. Nat. Rev. Nephrol. https:// doi.org/10.1038/s41581-020-00357-4 (2020).

22. Falavigna, M. et al. Guidelines for the pharmacological treatment of COVID-19. The task force/consensus guideline of the Brazilian Association of Intensive Care Medicine, the Brazilian Society of Infectious Diseases and the Brazilian Society of Pulmonology and Tisiology. Rev. Bras. Ter. Intens. https://doi.org/10.5935/0103-507X.20200039 (2020).

23. ESC Guidance for the Diagnosis and Management of CV Disease during the COVID-19 Pandemic. https://www.escardio.org/ Education/COVID-19-and-Cardiology/ESC-COVID-19-Guidance, https://www.escardio.org/Education/COVID-19-and-Cardi ology/ESC-COVID-19-Guidance (Accessed 21 March 2021).

24. Acevedo, G. R., Girard, M. C. \& Gómez, K. A. The unsolved jigsaw puzzle of the immune response in Chagas disease. Front. Immunol. https://doi.org/10.3389/fimmu.2018.01929 (2018).

25. Salvador, F. et al. Immunosuppression and Chagas disease; experience from a non-endemic country. Clin. Microbiol. Infect. Off. Publ. Eur. Soc. Clin. Microbiol. Infect. Dis. 21, 854-860. https://doi.org/10.1016/j.cmi.2015.05.033 (2015).

26. Pinazo, M.-J. et al. Immunosuppression and Chagas disease: A management challenge. PLoS Negl. Trop. Dis. 7, e1965. https://doi. org/10.1371/journal.pntd.0001965 (2013).

27. Marchese, V. et al. Strongyloides infection manifested during immunosuppressive therapy for SARS-CoV-2 pneumonia. Infection. https://doi.org/10.1007/s15010-020-01522-4 (2020).

28. Lier, A. J. et al. Case report: Disseminated strongyloidiasis in a patient with COVID-19. Am. J. Trop. Med. Hyg. 103, 1590-1592. https://doi.org/10.4269/ajtmh.20-0699 (2020).

\section{Acknowledgements}

We would like to thank the hospitals which are part of this collaboration, for supporting this Project. Especifically for this analysis, we thank the hospitals: Hospital Bruno Born; Hospital das Clínicas da UFMG; Hospital de Clínicas de Porto Alegre; Hospital Eduardo de Menezes; Hospital João XXIII; Hospital Julia Kubitschek; Hospital Metropolitano Dr. Célio de Castro; Hospital Nossa Senhora da Conceição; Hospital Regional Antônio Dias; Hospital Risoleta Tolentino Neves; Hospital Unimed-BH. We also thank all the clinical staff at those hospitals, who cared for the patients, and all undergraduate students who helped with data collection.

\section{Author contributions}

Substantial contributions to the conception or design of the work: M.S.M., I.M., I.J.R.O., M.C.P. and M.C.P.N. Substantial contributions to the acquisition, analysis, or interpretation of data for the work: I.M., M.S.M., L.M.O., M.C.P., R.T.S., M.H.C.G., I.J.R.O., L.S.M., R.L.R.C., A.G.S.N., A.N.R.M.B., A.N.B.A.S., A.A.C.M., B.L.F., C.A.C., F.D.A.R., F.A., F.A.B., G.F.N., H.D., H.C.G., J.C.A., L.B.M., L.B.Z., L.F.A., L.K., L.C.C., L.E.A.S., M.A.S.C., M.A.P.F., N.C.S.S., N.R.O., P.L.A., S.J.T.S.L., V.B.S., V.R.B.C., Y.C.R.F.A.B.M., R.M. and M.C.P.N. Drafted the work: I.M., M.S.M., M.C.P. and M.C.P.N. Revised the manuscript critically for important intellectual content: all authors. Final approval of the version to be published: all authors. Drafted the work: I.M., M.S.M., M.C.P. and M.C.P.N. Revised the manuscript critically for important intellectual content: all authors. Final approval of the version to be published: all authors. Agreement to be accountable for all aspects of the work in ensuring that questions related to the accuracy or integrity of any part of the work are appropriately investigated and resolved: M.S.M. and M.C.P.

\section{Funding}

This study was supported in part by Minas Gerais State Agency for Research and Development (Fundação de Amparo à Pesquisa do Estado de Minas Gerais-FAPEMIG) [Grant Number APQ-00208-20], National Institute of Science and Technology for Health Technology Assessment (Instituto de Avaliação de Tecnologias em SaúdeIATS)/National Council for Scientific and Technological Development (Conselho Nacional de Desenvolvimento Científico e Tecnológico-CNPq) [Grant Number 465518/2014-1], and CAPES Foundation (Coordenação de Aperfeiçoamento de Pessoal de Nível Superior) [Grant Number 88887.507149/2020-00].

\section{Competing interests}

The authors declare no competing interests.

\section{Additional information}

Supplementary Information The online version contains supplementary material available at https://doi.org/ 10.1038/s41598-021-96825-3. 
Correspondence and requests for materials should be addressed to M.S.M.

Reprints and permissions information is available at www.nature.com/reprints.

Publisher's note Springer Nature remains neutral with regard to jurisdictional claims in published maps and institutional affiliations.

(c) (i) Open Access This article is licensed under a Creative Commons Attribution 4.0 International cc) License, which permits use, sharing, adaptation, distribution and reproduction in any medium or format, as long as you give appropriate credit to the original author(s) and the source, provide a link to the Creative Commons licence, and indicate if changes were made. The images or other third party material in this article are included in the article's Creative Commons licence, unless indicated otherwise in a credit line to the material. If material is not included in the article's Creative Commons licence and your intended use is not permitted by statutory regulation or exceeds the permitted use, you will need to obtain permission directly from the copyright holder. To view a copy of this licence, visit http://creativecommons.org/licenses/by/4.0/.

(C) The Author(s) 2021 